\title{
RefLeXIONES EN TORNO A LA NATURALEZA Y EJECUTORIEDAD DE LOS DICTÁMENES EMITIDOS POR LOS COMITÉS DE SUPERVISIÓN de Tratados de Derechos Humanos en el ordenamiento ESPAÑOL: LA STS 1263/2018, DE 17 DE JULIO
}

\section{REFLECTIONS ON THE NATURE AND ENFORCEABILITY OF THE DECISIONS ISSUED BY THE COMMITTEES for the SUPERVISION OF HUMAN RIGHTS TREATIES IN tHE SPANISH LAW: STS 1263/2018, of JuLY 17}

Alberto Javier Macho Carro* Trabajo recibido el 30 de septiembre de 2019 y aprobado el 5 de diciembre de 2019

\section{Resumen}

En su reciente sentencia 1263/2018, de 17 de julio, el Tribunal Supremo español vino a afirmar el carácter obligatorio/vinculante de un dictamen emitido por el Comité para la eliminación de la discriminación contra la mujer (CEDAW, por sus siglas en inglés). Además, el supremo órgano jurisdiccional español encontró una vía para ejecutar ese dictamen en el ordenamiento jurídico nacional.

El presente trabajo pretende aportar algo de luz en el debate sobre la naturaleza jurídica y las posibilidades de ejecución de estas resoluciones, emitidas por los comités de derechos humanos en el marco de sus respectivos procedimientos de comunicaciones individuales.

Palabras clave: comités de derechos humanos, dictámenes, naturaleza jurídica, ejecutoriedad.

\begin{abstract}
In its recent judgement 1263/2018, July 17th, the Spanish Supreme Court confirmed the binding nature of a View passed by the Committee on the Elimination of Discrimination against Women (CEDAW). In addition, the Court found a way within the Spanish legal order to enforce this decision.

The aim of this work is trying to shed some light on the debate about the legal nature and enforceability of the Views issued by the Committees in charge of the supervision of human rights treaties within their individual communications procedures.
\end{abstract}

Key words: human rights committees, View, legal nature, enforceability.

\footnotetext{
* Alberto Javier Macho Carro. Investigador predoctoral de la Junta de Castilla y León en el área de Derecho Constitucional de la Universidad de Valladolid. Ex becario del Servicio de Doctrina Constitucional del Tribunal Constitucional de España. Máster en Derecho Constitucional por el Centro de Estudios Políticos y Constitucionales y la Universidad Internacional Menéndez Pelayo, España. Graduado en Derecho y en Administración y Dirección de Empresas por la Universidad de Valladolid, España. Investigación cofinanciada por el Fondo Social Europeo. Correo de contacto: albertojavier.macho@uva.es
} 


\section{INTRODUCCIÓN}

En su reciente sentencia 1263/2018, de 17 de julio, el Tribunal Supremo español vino a afirmar el carácter obligatorio/vinculante de un dictamen emitido por el Comité para la eliminación de la discriminación contra la mujer (CEDAW, por sus siglas en inglés). Además, el supremo órgano jurisdiccional español encontró una vía para ejecutar ese dictamen en el ordenamiento jurídico nacional.

El presente trabajo pretende aportar algo de luz en el debate sobre la naturaleza jurídica y las posibilidades de ejecución de estas resoluciones, emitidas por los comités de derechos humanos en el marco de sus respectivos procedimientos de comunicaciones individuales.

\section{HeCHOS QUE PROPICIARON LA SENTENCIA ${ }^{1}$}

La historia de doña Ángela González Carreño es, sin duda, la de una tragedia protagoniza por una madre coraje. Esta española contrajo matrimonio en 1996, dando a luz a su hija ese mismo año. Sin embargo, lejos de poder disfrutar de una pacífica vida conyugal, fue objeto de violencia física y psicológica por parte de su marido desde el primer momento.

Esta situación alcanzó puntos de extrema gravedad y propició la separación judicial de la pareja, estableciéndose la custodia de la hija menor en favor de su madre y un régimen inicial de visitas entre padre e hija supervisadas por los servicios sociales. No obstante, doña Ángela y su hija continuaron siendo objeto de insultos, amenazas y otros malos tratos por parte de su exmarido. Hechos que fueron denunciados en múltiples ocasiones.

Pese al acreditado comportamiento violento de su expareja, las autoridades judiciales españolas terminaron por autorizar un régimen de visitas entre padre e hija no vigiladas en mayo de 2002. Régimen al que los servicios sociales se opusieron en reitearadas ocasiones por su inadecuación para la menor. Finalmente, el 24 de abril de 2003, durante una de esas visitas no vigiladas, el padre mató a su hija y después se suicidó.

A raíz de estos trágicos acontecimientos, doña Ángela presentó ante el Ministerio de Justicia una reclamación de responsabilidad patrimonial del Estado por anormal funcionamiento de la Administración de Justicia. Esta reclamación fue rechazada y, a partir de ese momento, doña Ángela inició un largo periplo judicial pasando por la Audiencia Nacional, el Tribunal Supremo (TS) y el Tribunal Constitucional (TC), que inadmitió su recurso de amparo por carecer de especial trascendencia constitucional.

Agotados todos los recursos judiciales internos, la autora decidió presentar una comunicación individual ante el Comité para la eliminación de la discriminación contra la mujer. Este órgano fue instituido por el artículo 17 de la Convención sobre la eliminación de todas las formas de discriminación contra la mujer de 1979, un Tratado internacional ratificado por el Reino de España el 13 de diciembre de $1983^{2}$. Aunque el procedimiento de comunicaciones individuales ante este órgano se regula, como ocurre en todos los casos de estos comités, en otro Tratado internacional: el Protocolo Facultativo de 1999, también ratificado por España ${ }^{3}$.

\footnotetext{
1 Para una exposición más detallada de los hechos vid. el Dictamen del Comité para la Eliminación de la Discriminación contra la Mujer 16 de julio de 2014 emitido a raíz de la comunicación 47/2012, párrafos 2.1 a 2.21.

2 «BOE» núm. 69, de 21 de marzo de 1984, páginas 7715 a 7720.

3 «BOE» núm. 90, de 9 de agosto de 2001, páginas 29707 a 29710.
}

MACHO CARRO, Alberto Javier. Reflexiones en torno a la naturaleza y ejecutoriedad de los dictámenes emitidos por los Comités de Supervisión de Tratados de Derechos Humanos en el ordenamiento español: la STS 1263/2018, de 17 de julio. Revista Justicia y Derecho, Santiago, v. 2, n², 2019 
Pues bien, de conformidad con el artículo 7, párrafo 3, del Protocolo Facultativo, tras el procedimiento contradictorio correspondiente entre el Estado parte (España) y la autora de la comunicación, el CEDAW adoptó su dictamen el 16 de julio de 2014. En esta resolución el Comité afirma que el Estado español, por no actuar con la diligencia debida y aplicar una concepción estereotipada del régimen de visitas, infringió los derechos de la autora y su hija fallecida en virtud de los artículos 2 a), b), c), d), e) y f); 5 a); y 16, párrafo 1 d), de la Convención, leídos conjuntamente con el artículo 1 de la Convención y la recomendación general núm. 19 del Comité. Por estos motivos, el Comité recomendó a España, con respecto a la autora de la comunicación, otorgarle "una reparación adecuada y una indemnización integral y proporcional a la gravedad de la conculcación de sus derechos".

Con base en este dictamen, el 6 de febrero de 2015 doña Ángela presentó una nueva reclamación de responsabilidad patrimonial del Estado ante el Ministerio de Justicia por anormal funcionamiento de la justicia. Contra la desestimación de esta reclamación se interpuso, a su vez, recurso contencioso-administrativo ante la sección tercera de la Sala de lo contencioso-administrativo de la Audiencia Nacional. En la demanda se alegaba que la decisión administrativa determinó la vulneración de los derechos fundamentales contenidos en los artículos 14, 15, 18 y 24 de la Constitución española, vulneración que derivaría del hecho de no haber dado cumplimiento a lo establecido en el dictamen de 16 de julio de 2014 del CEDAW.

La Audiencia Nacional, pese a dejar constancia de que ya había rechazado una previa petición de reclamación de responsabilidad patrimonial del Estado por funcionamiento anormal de la Administración de justicia formulada por los mismos hechos base, admitió a trámite el recurso. Y ello por considerar que, «en la medida en que la acción ejercitada en el presente recurso se fundamenta sustancialmente en el dictamen del Comité para la eliminación de la discriminación contra la mujer de 16 de julio de 2014, no se aprecia la identidad a que se refiere el artículo 222.1 de la Ley de Enjuiciamiento Civil, razón por la cual no es de apreciar la existencia de cosa juzgada como causa de inadmisibilidad del presente recurso». Pese a todo, por sentencia de 2 de noviembre de 2016, la Audiencia Nacional desestimó la pretensión de la demandante por considerar, entre otras razones, que «no existe en el ordenamiento jurídico español un procedimiento que posibilite en este caso la eficacia ejecutiva de las recomendaciones contenidas en el dictamen del CEDAW, de modo que aunque para la emisión del referido dictamen del Comité fue parte e intervino el Estado español, oponiéndose a las pretensiones de la hoy demandante, lo cierto es que ha negado a la demandante la indemnización a que se refiere el dictamen del Comité y no consta haya proveído de los mecanismos necesarios para que los derechos de la Convención que ha ratificado puedan ser eficazmente tutelados».

Esta última sentencia de la Audiencia Nacional fue recurrida en casación ante el Tribunal Supremo, cuya Sección Cuarta de la Sala de lo contencioso-aministrativo dictó el 17 de julio de 2018 la sentencia número 1263/2018. Esta sentencia estimó parcialmente el recurso de la demandante y anuló tanto la resolución administrativa que desestimó la reclamación de responsabilidad patrimonial del Estado de 6 de febrero de 2015, como la sentencia de la Audiencia Nacional de 2 de noviembre de 2016. Además, impuso a la Administración demandada una condena por importe de 600.000 euros por los daños morales sufridos por la señora González Carreño. Para llegar a este resultado, la Sentencia del TS desplegó una argumentación que rompe en buena medida con la práctica jurisprudencial anterior y que ha dado lugar a un fértil debate jurídico tanto España como en el extranjero en relación con la recepción jurídica en los ordenamientos nacioanles de los dictámenes de estos comités. Estos razonamientos jurídicos, que pasaré a exponer a continuación, me servirán de base para efectuar algunas reflexiones en torno a la naturaleza y valor jurídico que en el ordenamiento español tienen los dictámenes emitidos por los comités encargados de la supervisión del cumplimiento de los tratados de derechos humanos. Tratados que han sido elaborados en el marco de Naciones Unidas y ratificados por España. 


\section{LA STS 1263/2018, DE 17 DE JULIO}

Mediante auto dictado el día 5 de junio de 2017 por la sección pimera de la Sala Tercera del TS se acordó admitir a trámite el recurso de casación interpuesto contra la sentencia de la Audiencia Nacional de 2 de noviembre de 2016 y se precisaron, como cuestiones en torno a las que existía un interés casacional objetivo, las siguientes.

«1. Cuál debe ser el cauce adecuado para solicitar del Estado español el cumplimiento de los dictámenes del Comité de la CEDAW (Convención sobre la Eliminación de Toda Forma de Discriminación Contra la Mujer), emitidos en los términos y por el procedimiento previsto en el Protocolo Facultativo de la Convención -ratificado por España-, cuando se contienen en tales dictámenes recomendaciones dirigidas a nuestras autoridades a fin de que reparen los daños derivados del incumplimiento constatado de los derechos previstos en la Convención.

2. O si, como sostiene la sentencia de instancia, la inexistencia de un procedimiento en el ordenamiento español que posibilite dotar de eficacia ejecutiva a aquellas recomendaciones y la ausencia de mecanismos necesarios para la tutela eficaz de los derechos reconocidos en la Convención no permiten exigir autónomamente el cumplimiento de aquellos dictámenes, más allá de la posible revisión -por los cauces correspondientes- de la decisión del Estado español de denegar la reparación solicitada».

En el Fundamento jurídico séptimo de la sentencia, el Tribunal Supremo afirma que el Dictamen del Comité de la CEDAW puede ser, por su propia naturaleza, el presupuesto que permita formular la reclamación de responsabilidad patrimonial de la demandada con el siguiente razonamiento:

«aunque ni la Convención ni el Protocolo regulan el carácter ejecutivo de los Dictámenes del Comité de la CEDAW, no puede dudarse que tendrán carácter vinculante/obligatorio para el Estado parte que reconoció la Convención y el Protocolo pues el artículo 24 de La Convención dispone que "los Estados partes se comprometen a adoptar todas las medidas necesarias en el ámbito nacional para conseguir la plena realización de los derechos reconocidos en la presente Convención". A tal efecto deberán tomarse también en consideración las previsiones del artículo 7.4 del Protocolo Facultativo sobre que "el Estado Parte dará la debida consideración a las opiniones del Comité, así como a sus recomendaciones, si las hubiere, y enviará al Comité, en un plazo de seis meses, una respuesta por escrito, especialmente información sobre toda medida que se hubiera adoptado en función de las opiniones y recomendaciones del Comité", reforzado por el reconocimiento expreso de la competencia del Comité de la CEDAW del artículo 1 del propio Protocolo Facultativo, voluntariamente asumido por España».

A esto, el supremo órgano jurisdiccional español añade que:

«el Dictamen emana de un órgano creado en el ámbito de una normativa internacional que, por expresa previsión del artículo 96 de la Constitución Española, forma parte de nuestro ordenamiento jurídico interno tras su ratificación y publicación en el Boletín Oficial del Estado; (ii) que, por imponerlo así el artículo 10.2 de nuestra Carta Magna, las normas relativas a los derechos fundamentales se interpretarán de conformidad con la Declaración Universal de Derechos Humanos y los tratados y acuerdos internacionales sobre las mismas materias ratificados por España».

Y que:

«el artículo 9.3 de la Constitución Española viene a afirmar que la Constitución garantiza, entre otros, el principio de legalidad y la jerarquía normativa, de manera que las obligaciones internacionales relativas a la ejecución de las decisiones de los órganos internacionales de control cuya competencia ha aceptado España forman parte de nuestro ordenamiento interno, una vez recibidas en los términos del 
artículo 96 de la Norma Fundamental, y gozan de la jerarquía que tanto este artículo -rango supralegalcomo el artículo 95 -rango infraconstitucional- les confieren».

Una argumentación que lleva al Tribunal Supremo a distinguir las diversas consecuencias jurídicas que se derivarían de entender los tratados internacionales de derechos humanos ratificados por España no solo como instrumentos interpretativos, sino también como normas jurídicas incardinadas en el ordenamiento español:

«no hay obstáculo para que la lesión de diversos derechos reconocidos por la Convención y que declara el Dictamen del Comité de la CEDAW, pueda y deba ser un elemento determinante para acreditar la posible vulneración de los correspondientes derechos fundamentales del recurrente pues el contenido de aquéllos constituye parte también del de éstos, formando el estándar mínimo y básico de los derechos fundamentales de toda persona en el Ordenamiento jurídico español, como resulta de la circunstancia de que los tratados y acuerdos internacionales que amparan ese Comité, además de ser Derecho interno propio con la jerarquía reconocida constitucionalmente, son también instrumentos hermenéuticos de los derechos fundamentales de la Constitución Española según su artículo 10.2».

Por esta vía, el Tribunal Supremo llega a la conclusión de que:

«el Dictamen del Comité de la CEDAW deberá ser tenido, en este caso y con sus particularidades, como presupuesto válido para formular una reclamación de responsabilidad patrimonial del Estado».

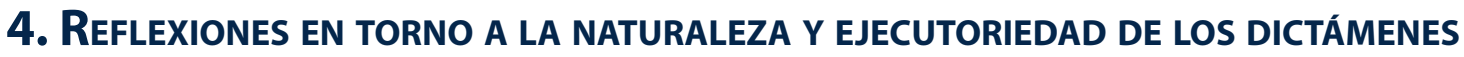 emitidos por los Comités de Supervisión de Tratados de Derechos Humanos en EL ORDENAMIENTO ESPAÑOL}

Hasta donde yo sé, ningún órgano jurisdiccional español había llegado tan lejos a la hora de afirmar la vinculatoriedad jurídica de las decisiones de estos comités, encontrando incluso una vía para su ejecución interna. Además, el que haya sido nada menos que el Tribunal Supremo -órgano cúspide del Poder judicial en España- quien haya efectuado esta interpretación, reviste la decisión de una especial trascendencia. Sin embargo, me parece que -aunque en términos de justicia material es difícil no aplaudir la decisión del TS, sobre teniendo en cuenta las trágicas circunstancias del caso- los razonamientos jurídicos de que se sirve la sentencia incurren en algunas confusiones. A tratar de aclararlas dedicaré las siguientes líneas de este trabajo.

El punto de partida indiscutible es que tanto la Convención sobre la eliminación de todas las formas de discriminación contra la mujer como su Protocolo Facultativo (el Protocolo o PF) son tratados internacionales que contaron con la preceptiva autorización de las Cortes Generales a la que se refiere el artículo 94.1 de la Constitución española (CE). Estos tratados fueron publicados en el Boletín Oficial del Estado y entraron en vigor en nuestro país el 4 de febrero de 1984 y el 6 de octubre de 2001, de acuerdo con sus respectivos artículos 27 y 16.

Como tales tratados internacionales válidamente celebrados y ratificados por España, de acuerdo con el artículo 96 CE forman parte del ordenamiento jurídico interno y sus disposiciones «sólo podrán ser derogadas, modificadas o suspendidas en la forma prevista en los propios tratados o de acuerdo con las normas generales del Derecho internacional». Es decir, que gozan de una especial fuerza pasiva frente

4 La cursiva es nuestra.

MACHO CARRO, Alberto Javier. Reflexiones en torno a la naturaleza y ejecutoriedad de los dictámenes emitidos por los Comités de Supervisión de Tratados de Derechos Humanos en el ordenamiento español: la STS 1263/2018, de 17 de julio. Revista Justicia y Derecho, Santiago, v. 2, n², 2019 
a las leyes internas. Además, en ningún caso se ha cuestionado que estos tratados pudieran contener estipulaciones contrarias a la Constitución, por lo que su ratificación no ha exigido la previa revisión constitucional a que se refiere el artículo 95 CE -disposición de la que puede deducirse sin dificultad la subordinación jerárquica de los tratados internacionales a la Norma Fundamental dentro del ordenamiento español-.

Por tanto, no hay duda de que las normas jurídicas contenidas en las disposiciones tanto de la Convención como del Protocolo forman parte de nuestro ordenamiento jurídico. Es más, podemos afirmar que se trata de normas jurídicas de carácter supralegal, tanto por esa especial fuerza pasiva que les concede la propia Constitución española, como porque así lo establece el artículo 31 de la Ley 25/2014, de 27 de noviembre, de tratados y otros acuerdos internacionales. Según este precepto, «las normas jurídicas contenidas en los tratados internacionales válidamente celebrados y publicados oficialmente prevalecerán sobre cualquier otra norma del ordenamiento interno en caso de conflicto con ellas, salvo las normas de rango constitucional». Aunque, como afirma CANOSA USERA, sea discutible que una ley pueda determinar esta posición jerárquica dentro del sistema de fuentes 5 . En cualquier caso, mucho antes de la entrada en vigor de esta Ley de tratados, reputados constitucionalistas ya vislumbramban la posibilidad de la primacía de (al menos) algunos de los tratados internacionales que contempla nuestra Carta Magna6.

Ahora bien, desde mi punto de vista, una cosa es afirmar que las disposiciones de los tratados aprobados con autorización de las Cortes Generales tienen carácter supralegal. Pero es muy distinto deducir de tal carácter -como ha hecho el Tribunal Supremo- que también «las obligaciones internacionales relativas a la ejecución de las decisiones de los órganos internacionales de control cuya competencia ha aceptado España forman parte de nuestro ordenamiento interno» y, además, que lo hacen con rango supralegal.

Es evidente que España ha reconocido la competencia del CEDAW para recibir y examinar las comunicaciones (art. 1 PF) que pudieran presentar «personas o grupos de personas que se hallen bajo la jurisdicción del Estado Parte y que aleguen ser víctimas de una violación por ese Estado Parte de cualquiera de los derechos enunciados en la Convención» (art. 2 PF). Sin embargo, también es cierto que ningún artículo de la Convención ni del Protocolo Facultativo atribuye fuerza ejecutoria directa a los dictámenes del Comité. Y ello a pesar de que España se ha comprometido, de acuerdo con el artículo 2 de la Convención, a adoptar medidas todo tipo de medidas encaminadas a eliminar la discriminación contra la mujer ${ }^{7}$ y, de acuerdo con el artículo 7.4 PF, a dar la «debida consideración a las opiniones del Comité, así

5 CANOSA, R (2015), p. 88.

6 En este sentido, DE OTTO, I. (1987), p. 125, afirmó que: "Esta resistencia de los tratados frente a las leyes ha llevado a mantener la tesis de que aquéllos ocupan una posición superior a la de éstas, de modo que vendrían a constituir un escalafón infraconstitucional y supralegal, esto es, un escalafón entre la Constitución y la ley. La tesis, loable en cuanto negación de prejuicios nacionalistas, tiene el obvio inconveniente de que no sería aplicable a los tratados suscritos únicamente por el Gobierno, pues una norma es superior a otra cuando tiene frente a ella fuerza activa y fuerza pasiva, y ya hemos visto que sin la previa autorización de las Cortes no es posible derogar o modificar una ley mediante un tratado [art. 94.1 e) CE], lo que significa que los tratados suscritos sólo por el Gobierno carecen de fuerza activa frente a la ley".

7 En concreto, el artículo 2 del Protocolo Facultativo establece que: Los Estados Partes condenan la discriminación contra la mujer en todas sus formas; convienen en seguir, por todos los medios apropiados y sin dilaciones, una política encaminada a eliminar la discriminación contra la mujer y, con tal objeto, se comprometen a: a) Consagrar, si aún no lo han hecho, en sus Constituciones nacionales y en cualquier otra legislación apropiada el principio de la igualdad del hombre y de la mujer y asegurar por Ley u otros medios apropiados la realización práctica de ese principio. b) Adoptar medidas adecuadas, legislativas y de otro carácter, con las sanciones correspondientes, que prohíban toda discriminación contra la mujer. c) Establecer la protección jurídica de los derechos de la mujer sobre una base de igualdad con los del hombre y garantizar, por conducto de los Tribunales nacionales o competentes y de otras instituciones públicas, la protección efectiva de la mujer contra todo acto de discriminación. d) Abstenerse de incurrir en todo acto o práctica de discriminación contra la mujer y velar porque las autoridades e instituciones

MACHO CARRO, Alberto Javier. Reflexiones en torno a la naturaleza y ejecutoriedad de los dictámenes emitidos por los Comités de Supervisión de Tratados de Derechos Humanos en el ordenamiento español: la STS 1263/2018, de 17 de julio. Revista Justicia y Derecho, Santiago, v. 2, n², 2019 
como a sus recomendaciones, si las hubiere». Además de a enviar al Comité «en un plazo de seis meses, una respuesta por escrito, especialmente información sobre toda medida que se hubiera adoptado en función de las opiniones y recomendaciones del Comité».

Y es que ni siquiera las sentencias dictadas por órganos internacionales de naturaleza inequívocamente jurisdiccional, como es el caso del Tribunal Europeo de Derechos Humanos, han gozado de fuerza ejecutiva interna hasta que el legislador español ha establecido un cauce procedimental específico para ello8. Como señala QUERALT JIMÉNEZ: «el Tribunal es un órgano de carácter internacional cuya configuración le impide realizar innovación alguna en los ordenamientos internos de los Estados parte, porque, por voluntad de los fundadores del sistema de protección, el TEDH no cuenta con los instrumentos coercitivos necesarios para ello» ${ }^{9}$. Y es que, «es comúnmente aceptado que las Sentencias del Tribunal de Estrasburgo son declarativas -aquí en contraposición a ejecutivas-» ${ }^{10}$. Por este motivo, la posibilidad de que las decisiones adoptadas por el CEDAW u otros comités equivalentes puedan ser ejecutadas internamente sin que medie una legislación nacional que así lo prevea parece dificil de sostener jurídicamente. Así lo entienden también VAN ALEBEEK y NOLLKAEMPER cuando aseveran que: «the judiciary may find it difficult if not impossible to implement the recommended remedy in the absence of national legislation allowing Views to take legal effect domesticallys ${ }^{11}$.

Ahora bien, iquiere esto decir que los pronunciamientos emitidos por estos comités, cuya competencia para declarar la violación de unos derechos que gozan de en España de rango legal o supralegal, carecen de toda virtualidad jurídica en nuestro ordenamiento? La cuestión no es sencilla ni pacífica entre la doctrina.

TRINIDAD NúÑEZ afirma que el hecho de «que un órgano no tenga carácter jurisdiccional y que, en consecuencia, sus decisiones no tengan ejecutoriedad, no significa que las mismas no sean obligatorias para el Estado respecto al que se dictan» ${ }^{12}$. Sin embargo, esta misma autora pone de manifiesto que la jurisprudencia española no ha venido sosteniendo tradicionalmente esta tesis ${ }^{13}$, habiendo llegado a afirmar el Tribunal Supremo con relación al Comité de Derechos Humanos ${ }^{14}$ (Comité DDHH) que:

«sus resoluciones o dictámenes carecen de aptitud para crear una doctrina o precedente que pudiera vincular a esta Sala de lo Penal del Tribunal Supremo, de modo que el efecto jurídico que puede producir queda reducido a lo expuesto: esa declaración de existencia de vulneración»15.

públicas actúen de conformidad con esta obligación. e) Tomar todas las medidas apropiadas para eliminar la discriminación contra la mujer practicada por cualesquiera personas, organizaciones o empresas. f) Adoptar todas las medidas adecuadas, incluso de carácter legislativo, para modificar o derogar Leyes, Reglamentos, usos y prácticas que constituyan discriminación contra la mujer. g) Derogar todas las disposiciones penales nacionales que constituyan discriminación contra la mujer.

8 Cosa que no ocurrió hasta la apertura del recurso de revisión (art. 954.3 LECRIM) operada por Ley 41/2015, de 5 de octubre, de modificación de la Ley de Enjuiciamiento Criminal para la agilización de la justicia penal y el fortalecimiento de las garantías procesales.

9 QUERALT JIMÉNEZ, A. (2008), p. 15.

10 QUERALT JIMÉNEZ, A. (2008), p. 8.

11 VAN ALLEBEEK, R. y NOLLKAEMPER, A.: «The legal status of decisions by human rights treaty bodies in national law», en KELLER, H. y ULFSTEIN, G. (2012), p. 377.

12 TRINIDAD NÚÑEZ, P. (2009), p. 342.

13 TRINIDAD NÚÑ̃EZ, P. (2009), pp. 340-344.

14 Este comité es el órgano encargado de tutelar el cumplimento de las obligaciones establecidas en el Pacto Internacional de Derechos Civiles y Políticos de 1966, a cuya imagen y semejanza se han creado el resto de los comités competentes para conocer de comunicaciones individuales.

15 STS 141/2005, de 11 de febrero de 2005, Sala de lo Penal, F.J. 2. La sentencia se refiere a los dictámenes del Comité de Derechos Humanos, pero se entiende que la argumentación es perfectamente extensible a los emitidos por otros comités equivalentes.

MACHO CARRO, Alberto Javier. Reflexiones en torno a la naturaleza y ejecutoriedad de los dictámenes emitidos por los Comités de Supervisión de Tratados de Derechos Humanos en el ordenamiento español: la STS 1263/2018, de 17 de julio. Revista Justicia y Derecho, Santiago, v. 2, n² 2, 2019 
Igualmente, el Tribunal Constitucional, en el fundamento jurídico cuarto de su STC 116/2006, de 24 de abril, declara (también en relación con el Comité DDHH) que:

«las 'observaciones' que en forma de dictamen emite el Comité no son resoluciones judiciales, puesto que el Comité no tiene facultades jurisdiccionales (como claramente se deduce de la lectura de los arts. 41 y 42 del Pacto), y sus dictámenes no pueden constituir la interpretación auténtica del Pacto, dado que, en ningún momento, ni el Pacto ni el Protocolo facultativo le otorgan tal competencia».

A mi modo de ver, TRINIDAD NÚÑEZ tiene toda la razón cuando irónicamente se pregunta que «si el Comité de Derechos Humanos, el órgano creado por el PIDESC para llevar a cabo su supervisión y control -y que tiene entre sus facultades la elaboración de Observaciones generales sobre el contenido del Pacto y su aplicación- carece de competencia para interpretar de forma fehaciente ("interpretación auténtica" en palabras del Tribunal), el contenido del Pacto ¿quién tendrá, entonces, esta facultad?» ${ }^{16}$. Y es que, para poder declarar que una determinada actuación estatal ha vulnerado o no alguno de los derechos contemplados en el convenio de que se trate, estos comités tienen necesariamente que interpretar el texto de dichos tratados.

Ahora bien, concuerdo con GUTIÉRREZ ESPADA cuando afirma que calificar como «obligatorias» las decisiones de estos comités tampoco parece lo más adecuado, por cuanto esto supondría equipararlas a las sentencias de un tribunal ${ }^{17}$. Es el caso, de nuevo, las sentencias del TEDH, cuya obligatoriedad viene expresamente establecida por el artículo 46 del Convenio de Roma (1950) ${ }^{18}$. Aunque hay autores que han defendido esa equiparación ${ }^{19}$, lo cierto es que, con carácter general, la doctrina internacionalista acepta el carácter no vinculante (not binding) de estas decisiones ${ }^{20}$. Y es que, «es verdad, ciertamente, que el hecho de que nuestro país haya aceptado libremente la competencia de un Comité para pronunciarse sobre el fondo de las denuncias que [...] particulares presenten contra Estados miembros por violación de los derechos y libertades reconocidos por el tratado en cuestión, haría en principio incongruente que el Estado denunciado no aplicase el dictamen final al que llegara el Comité, muy en particular de ser condenatorio. Y sin embargo también es verdad que los Estados que libremente aceptan esa competencia del Comité lo hacen en el entendido y sabiendo que sus decisiones son formalmente puramente recomendatorias y no generan para él obligaciones exigibles jurídicamente» ${ }^{21}$.

Ahora bien, lo que me parece innegable es que la interpretación que efectúan estos comités de los tratados cuyo cumplimiento supervisan debe ser calificada como auténtica. Al menos en el sentido de ser la interpretación más autorizada de estos textos legales. Una interpretación que, por tanto, ha de jugar un papel determinante por vía del artículo 10.2 CE, que establece que: «las normas relativas a los derechos fundamentales y a las libertades que la Constitución reconoce se interpretarán de conformidad con la Declaración Universal de Derechos Humanos y los tratados y acuerdos internacionales sobre las mismas materias ratificados por España».

16 TRINIDAD NÚÑ̃EZ, P. (2009), p. 341.

17 GUTIÉRREZ ESPADA, C. (2018), pp. 841-842.

18 En este sentido, QUERALT JIMÉNEZ, A. (2008), p. 10, escribe que: «la naturaleza obligatoria de las sentencias del TEDH viene claramente establecida en el art. 46.1 CEDH. En virtud de este precepto los Estados quedan jurídicamente obligados a acatar las sentencias firmes del TEDH. Esta obligación jurídica prevista en el art. 46.1 CEDH no debe ser entendida de ningún modo como una mera cláusula de estilo en la redacción del $\mathrm{CEDH}$, sino que esta obligatoriedad es real y efectiva, tal y como demuestra el hecho de que viene acompañada, además, de un mecanismo de supervisión por el que pretende garantizarse su efectivo cumplimiento (Art. 46.2 CEDH), función que desempeña el Comité de Ministros».

19 Es el caso de FERNÁNDEZ DE CASADEVANTE ROMANÍ, C. (2009), pp. 179-198 citado por GUTIÉRREZ ESPADA, C. (2018), pp. 841-842.

20 Para un análisis de las distintas posturas y sus respectivos matices vid. ULFSTEIN, G. «Indivdual complaints», en KELLER, H. y ULFSTEIN, G. (2012), pp. 92 y ss.

21 GUTIÉRREZ ESPADA, C., (2018), pp. 842.

MACHO CARRO, Alberto Javier. Reflexiones en torno a la naturaleza y ejecutoriedad de los dictámenes emitidos por los Comités de Supervisión de Tratados de Derechos Humanos en el ordenamiento español: la STS 1263/2018, de 17 de julio. Revista Justicia y Derecho, Santiago, v. 2, n², 2019 
El propio Tribunal Constitucional, aunque se ha negado a calificar de auténtica la interpretación efectuada por estos comités, lo cierto es que la ha puesto en valor en más de una ocasión. Un ejemplo de esto se encuentra en el fundamento jurídico quinto de la misma STC 116/2006, de 24 de abril:

«ahora bien, el que los dictámenes del Comité no sean resoluciones judiciales, no tengan fuerza ejecutoria directa y no resulte posible su equiparación con las Sentencias del Tribunal Europeo de Derechos Humanos, no implica que carezcan de todo efecto interno en la medida en que declaran la infracción de un derecho reconocido en el Pacto y que, de conformidad con la Constitución, el Pacto no sólo forma parte de nuestro Derecho interno, conforme al art. 96.1 CE, sino que además, y por lo que aquí interesa, las normas relativas a los derechos fundamentales y libertades públicas contenidas en la Constitución deben interpretarse de conformidad con los tratados y acuerdos internacionales sobre las mismas materias ratificados por España (art. 10.2 CE); interpretación que no puede prescindir de la que, a su vez, llevan a cabo los órganos de garantía establecidos por esos mismos tratados y acuerdos internacionales (STC 81/1989, de 8 de mayo, FJ 2)».

\section{Conclusiones}

En definitiva, pese a que no podemos sino aplaudir en términos de justicia material el resultado alcanzado por el Tribunal Supremo en su sentencia 1263/2018, de 17 de julio; lo cierto es que este órgano jurisdiccional se ha visto obligado a utilizar un cauce procesal de forma extremadamente generosa para poder ejecutar el dictamen de la CEDAW. Y es que, mientras el legislador español no tome conciencia de que la ratificación de tratados internacionales sobre derechos humanos ha de ser mucho más que una mera "operación de imagen" de cara a la sociedad internacional. De que estas ratificaciones llevan aparejadas la asunción de importantes obligaciones, entre las que destaca la de «instituir un marco normativo, procesal e institucional adecuado que permita la realización efectiva de los derechos reconocidos» ${ }^{22}$. La jurisdicción tendrá muy difícil encontrar vías de ejecución para los dictámenes de los comités encargados de la supervisión del cumplimiento de estos tratados.

Ahora bien, una cosa es afirmar que los dictámenes emitidos por el CEDAW u otros comités equivalentes carezcan de carácter ejecutivo en el ordenamiento español si no se habilitan previamente los cauces procesales oportunos para ello. Sin embargo, esto no quiere decir que estos pronunciamientos carezcan de toda virtualidad jurídica, pues los mismos cumplen una función hermenéutica trascendental cuando de interpretar los derechos constitucionales se refiere. Un valor que viene impuesto por la propia Constitución española en su artículo 10.2 y que, aunque -en mi opinión- de forma excesivamente tímida, ha sido reconocida por el supremo intérprete de nuestra Norma fundamental, el Tribunal Constitucional.

\section{Bibliografía}

CANOSA, R. (2015): El control de convencionalidad, Thomson Reuters, Madrid.

DE OTTO, I. (1987): Derecho Constitucional. Sistema de fuentes, Ariel, 13a impresión.

FERNÁNDEZ DE CASADEVANTE ROMANÍ, C. (2009): «La ejecución de sentencias y decisiones de tribuna-

22 JIMÉNEZ GARCÍA, F. (2014), 80.

MACHO CARRO, Alberto Javier. Reflexiones en torno a la naturaleza y ejecutoriedad de los dictámenes emitidos por los Comités de Supervisión de Tratados de Derechos Humanos en el ordenamiento español: la STS 1263/2018, de 17 de julio. Revista Justicia y Derecho, Santiago, v. 2, n², 2019 
les y comités», en ESCOBAR HERNÁNDEZ, C. y PASTOR PALOMAR, A. (Coords.): Los derechos humanos en la sociedad internacional del siglo XXI, vol. 2, Colección Escuela Diplomática.

GUTIÉRREZ ESPADA, C. (2018): Cuadernos de Derecho Transnacional, (octubre 2018), vol. 10, no 2.

JIMÉNEZ GARCÍA, F. (2014): «Tomarse en serio el Derecho internacional de los derechos humanos», Revista Española de Derecho Constitucional, núm. 101, mayo-agosto.

QUERALT JIMÉNEZ, A (2008): La interpretación de los derechos: del tribunal de Estrasburgo al Tribunal Constitucional, CEPC, Madrid.

TRINIDAD NúÑEZ, P. (2009): «La aplicación judicial en España de las decisiones de los órganos de base convencional de supervisión de derechos humanos creados en el seno de las Naciones Unidas» en La aplicación del Derecho internacional de los derechos humanos en el Derecho español, MARIÑO MÉNENDEZ, F. (coord.), UC3, Madrid.

KELLER, H. y ULFSTEIN, G. (2012): UN Human Rights Treaty Bodies: Law and Legitimacy, Cambridge University Press.

\section{Normativa}

«BOE» núm. 69, de 21 de marzo de 1984, páginas 7715 a 7720.

«BOE» núm. 90, de 9 de agosto de 2001, páginas 29707 a 29710.

Convención sobre la Eliminación de Toda Forma de Discriminación Contra la Mujer de 1979

Constitución española de 1978

Dictamen del Comité para la Eliminación de la Discriminación contra la Mujer 16 de julio de 2014 emitido a raíz de la comunicación 47/2012, párrafos 2.1 a 2.21 .

Ley 25/2014, de 27 de noviembre, de tratados y otros acuerdos internacionales.

Ley de Enjuiciamiento Criminal para la agilización de la justicia penal y el fortalecimiento de las garantías procesales.

Pacto Internacional de Derechos Civiles y Políticos de 1966

Protocolo Facultativo de la Convención sobre la Eliminación de Toda Forma de Discriminación Contra la Mujer de 1999

\section{JURISPRUDENCIA}

STC $81 / 1989$, de 8 de mayo

STC 116/2006, de 24 de abril

STS 141/2005, de 11 de febrero de 2005

STS 1263/2018, de 17 de julio

MACHO CARRO, Alberto Javier. Reflexiones en torno a la naturaleza y ejecutoriedad de los dictámenes emitidos por los Comités de Supervisión de Tratados de Derechos Humanos en el ordenamiento español: la STS 1263/2018, de 17 de julio. Revista Justicia y Derecho, Santiago, v. 2, n², 2019 